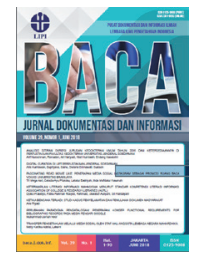

\title{
Preservasi kearifan lokal naskah pararaton Ken Arok dan Ken Dedes: studi naskah pada novel Arok Dedes
}

\author{
Larasati Tri Kurnia $^{1 *}$; Lydia Christiani ${ }^{2}$ \\ 1,2Program Studi Ilmu Perpustakaan, Fakultas Ilmu Budaya, Universitas Diponegoro \\ *Korespondensi: larasatitk@gmail.com
}

Diajukan: 23-10-2020; Direview: 18-02-2021; Diterima: 21-04-2021; Direvisi: 31-05-2021

\begin{abstract}
The research purpose is to understanding and analyzes the preservation of local wisdom values inside the novel Arok Dedes' representation. The method used in this research is qualitative, with discourse analysis as a data analysis method. Its results showed that Arok Dedes'novel is a new document production from an old document, the Pararaton manuscript. The activity document production from the Pararaton manuscript to the novel Arok Dedes is an effort to preserve the local content in the Pararaton manuscript because it considers the tastes of a global society. The process of preservation local content in the Pararaton manuscript showed several stages, the stages are recognition and identification, validation, recording and documentation, storage, transfer, and dissemination. Through the local content preservation stage, the value of local wisdom which is implicit in moral messages in the Pararaton manuscript can be described in the novel Arok Dedes, so the wisdom values with implicit moral messages in Ken Arok and Ken Dedes'folklore can be sustained from generation to generation.
\end{abstract}

\begin{abstract}
ABSTRAK
Penelitian ini bertujuan untuk memahami dan menganalisis preservasi nilai-nilai kearifan lokal naskah Pararaton: Sebuah novel tentang Ken Arok dan Ken Dedes. Metode penelitian yang digunakan adalah kualitatif, dengan metode analisis data menggunakan analisis wacana. Hasil penelitian ini menunjukan bahwa novel Arok Dedes merupakan produksi dokumen baru dari dokumen lama, yaitu naskah Pararaton. Kegiatan produksi dokumen dari naskah Pararaton ke novel Arok Dedes merupakan upaya kegiatan preservasi local content yang ada pada naskah Pararaton dengan mempertimbangkan selera masyarakat masa kini. Proses preservasi local content pada naskah Pararaton melewati beberapa tahapan, yaitu recognition and identification, validation, recording and documentation, storage, transfer, and dessimination. Melalui tahapan preservasi local content, maka nilai kearifan lokal yang syarat akan pesan moral pada naskah Pararaton dapat digambarkan dalam novel Arok Dedes, sehingga nilai kearifan yang syarat akan pesan moral dalam cerita rakyat Ken Arok dan Ken Dedes dapat lestri dari generasi ke generasi.
\end{abstract}

Keywords: Preservation document; Local wisdom; Heritage; Folklore; Praraton manuscript; Indonesia

\section{PENDAHULUAN}

Indonesia memiliki keanekaragaman budaya, sehingga Indonesia memiliki informasi lokal yang berlimpah yang memiliki keunikannya masing-masing. Informasi lokal atau yang biasa disebut local content adalah informasi penting yang dimiliki oleh sekelompok orang berdasarkan tempat tinggal, budaya, bahasa, agama, etnis, atau bidang minat yang akan berubah seiring waktu sehingga local content memiliki keterkaitan dengan indigeneous knowledge (OECD/ISOC/UNESCO, 2011). Indigeneous knowledge merupakan pengetahuan yang dimiliki oleh masyarakat mengenai budaya dan masyarakat lokal yang terdapat keunikan didalamnya (World-Bank, 1998).

Local content dan indigeneous knowledge merupakan informasi yang dimiliki oleh masyarakat setempat. Local content merupakan informasi yang sudah didokumentasi hingga menjadi suatu konten, sedangkan indigeneous knowledge merupakan pengetahuan yang dimiliki suatu individu atau kelompok. Salah satu bentuk dari local content adalah cerita rakyat. Cerita rakyat dapat 
dikatakan local content karena tidak memiliki perbedaan yang signifikan dengan ciri-ciri cerita rakyat. Menurut Hidayat, Sulistyowati, \& Rokhmansyah (2019), cerita rakyat disebarkan melalui mulut ke mulut, bersifat tradisional, cerita rakyat tidak mementingkan fakta dan kebenaran sehingga memiliki beberapa versi, bersifat anonim atau penulisnya tidak diketahui, mempunyai bentuk berpola, misalnya penggunaan kata-kata klise, contohnya "seperti bulan empat belas hari" untuk menyatakan kecantikan seseorang, memiliki kegunaan dalam kehidupan bersama, bersifat pralogis, milik bersama dari kolektif tertentu. Oleh karena itu, cerita rakyat terkandung nilai-nilai kearifan lokal yang digunakan sebagai pembelajaran.

Nurgiyantoro dalam Jayapada, Faisol, \& Kiptiyah (2017) berpendapat bahwa cerita rakyat merupakan cerita yang berasal dari warisan nenek moyang di masyarakat setempat sebagai media untuk menyampaikan pesan moral. Cerita rakyat yang merupakan local content, mengandung nilainilai kearifan lokal, sehingga naskah kuno yang di dalamnya terdapat cerita rakyat merupakan local content. Terdapat banyak sekali naskah kuno yang syarat akan local content, salah satu contohnya adalah Naskah Pararaton yang menuturkan mengenai cerita rakyat Ken Arok dan Ken Dedes.

Dewi (2013) menyatakan bahwa naskah Pararaton dapat dikatakan local content karena naskah Pararaton merupakan warisan dari nenek moyang yang dilestarikan dengan cara menuliskannya menjadi sastra Jawa, dan karya tersebut digolongkan sebagai historiografi tradisional atau local tradition. Menurut Munandar (2011), naskah Pararaton terbagi menjadi dua bagian. Bagian pertama menceritakan mengenai kehidupan Ken Arok dari kecil hingga wafat di kedaton Tumapel Singasari, sedangkan bagian kedua mengisahkan raja-raja Singasari hingga raja terakhir Majapahit yang merupakan raja yang sedang naik takhta saat naskah Pararaton sedang ditulis, yaitu tahun 1481 Masehi. Naskah Pararaton tentang Ken Arok diangkat kembali pada novel Arok Dedes karya Pramoedya Ananta Toer yang diterbitkan pertama kali pada tahun 1999 oleh penerbit Hasta Mitra. Pararaton telah mengilhami novel Arok Dedes (Dewi, 2013).

Bahar \& Mathar (2015) berpendapat bahwa mengkaji ulang isi yang terkandung dalam naskah kuno merupakan salah satu upaya pelestarian sehingga dapat dimanfaatkan oleh masyarakat. Dapat dikatakan bahwa kegiatan pelestarian tidak hanya merawat naskah kuno secara fisik, namun juga merepresentasikan kembali konten yang ada pada dokumen yang sudah tidak banyak peminatnya ke dalam format dokumen yang lebih baru dan lebih mengikuti perkembangan zaman serta sesuai dengan minat masyarakat. Konten nilai-nilai kearifan lokal sebagai local content pada naskah kuno dapat lestari dari generasi ke generasi, sebagaimana nilai-nilai kearifan lokal naskah Pararaton dilestarikan dalam representasi baru pada novel Arok Dedes karya Pramoedya Ananta Toer. Kegiatan menuliskan kembali yang dilakuan oleh Pramoedya Ananta Toer merupakan salah satu bentuk pelestarian kearifan lokal pada local content naskah Pararaton.

Penulisan kembali mengenai cerita rakyat merupakan wujud representasi baru nilai-nilai kearifan lokal dalam naskah Pararaton pada novel Arok Dedes yang membuka titik akses baru untuk nilainilai kearifan lokal pada naskah Pararaton. Representasi cerita Ken Arok dan Ken Dedes dalam novel Arok Dedes juga merupakan bentuk dari kemas ulang informasi dalam dokumen yang lebih sesuai dengan selera masyarakat masa kini. Fatmawati (2009) mengatakan bahwa kemas ulang informasi berfungsi untuk memudahkan perolehan suatu informasi, cepatnya penemuan kembali suatu informasi, serta sebagai alat untuk penerjemahan yang efektif dan efisien.

Membuka titik akses cerita Ken Arok dan Ken Dedes dalam novel Arok Dedes perlu dilakukan oleh peneliti. Tujuannya agar cerita Ken Arok dan Ken Dedes dapat terus digunakan dan dilestarikan oleh masyarakat masa kini. Novel Arok Dedes akan diamati sebagai objek yang menjadi wadah preservasi nilai-nilai kearifan lokal pada local content naskah Pararaton. Penelitian ini bertujuan untuk melihat nilai-nilai kearifan lokal yang direpresentasikan kembali melalui novel Arok Dedes, serta melihat proses pelestarian melalui kegiatan produksi dokumen lama ke dokumen baru. 


\section{TINJAUAN PUSTAKA}

Penelitian Fadli, Erwin, \& Prahatmaja (2012) mengkaji kegiatan pelestarian tradisi Pasambahan melalui kegiatan exchange of indigenous knowledge antar masyarakat Koto Salayan Kurai Limo Jorong, Kota Bukittinggi dengan teori yang dikemukakan oleh World-Bank (1998) untuk melihat kegiatan exchange of indigenous knowledge melalui beberapa tahapan, yaitu recognition and identification, validation, recording and documentation, storage, transfer and dissemination. Penelitian tersebut menunjukkan bahwa adanya tradisi Pasambahan dalam upacara tradisional, terdapat pengetahuan mengenai tradisi Pasambahan yang digunakan sebagai alat komunikasi dalam upacara Malapeh Marapulai, pengetahuan mengenai tradisi Pasambahan didokumentasikan dalam bentuk kaset, buku, dan video, pertukaran pengetahuan dilakukan dengan cara sosialisasi dan penyebaran pengetahuan mengenai tradisi Pasambahan dilakukan dengan cara diadakannya kompetisi antar desa, seminar, lokakarya, dan publikasi di situs resmi Bukittinggi.

Penelitian Hamid (2013) mengkaji mengenai upaya preservasi non-fisik pada manuskrip budaya Sasak dengan cara menerjemahkannya agar nilai-nilai budaya masyarakat Sasak dapat dipahami oleh masyarakat. Isi manuskrip terdapat nilai budaya yang didalamnya mencakup lima masalah pokok kehidupan manusia, yaitu hakikat hidup, karya, kedudukan manusia dalam ruang dan waktu, hubungan manusia dengan alam, dan hubungan manusia dengan sesama. Hasil penelitian menunjukkan bahwa manuskrip Lombok memiliki nilai budaya positif yang dapat digunakan sebagai acuan hidup, yaitu mengenai hakikat hubungan manusia dengan sesama dan hubungan manusia dengan Tuhan.

Penelitian Wildan (2013) memfokuskan pada konten naskah kuno sebagai titik fokus sebagai upaya pelestarian dengan media yang berbeda pada nilai kearifan lokal yang di temukan pada Novel Seulusoh karya D. Kemalawati - yang digambarkan melalui pengalaman hidup yang ada pada novel untuk mengidentifikasi kearifan lokal yang terdapat dalam novel tersebut. Hasil penelitian menunjukkan bahwa terdapat kearifan lokal pada Novel Seulusoh karya D. Kemalawati berupa perayaan hari suci seperti Ramadhan, meugang, dan lebaran, serta adanya penggambaran mengenai pembuatan dan penyajian makanan tradisional seperti ie bu peudah dan timphan. Hal tersebut menunjukkan ada fungsi kearifan lokal, yaitu untuk mempertahankan nilai tradisi dan adat istiadat, kemampuan membaca tanda-tanda alam, dan mempertahankan harga diri.

Penelitian Dewi (2013) mengkaji tentang local content naskah Pararaton dalam novel Arok Dedes. Novel Arok Dedes sebagai bentuk dinamika sastra yang merupakan bentuk terkini dari naskah Pararaton akibat globalisasi. Penelitian tersebut memperlihatkan titik akses baru dari naskah Pararaton dengan adanya pengaruh globalisasi. Hasil penelitian menunjukkan bahwa peneliti belum melakukan transformasi nilai-nilai kearifan lokal ke dalam novel Arok Dedes sebagai bentuk kegiatan preservasi local content. Hal ini yang menjadi kajian dalam penelitian ini. Novel Arok Dedes diamati sebagai objek yang menjadi wadah preservasi nilai-nilai kearifan lokal pada local content naskah Pararaton.

\section{METODE}

Penelitian ini menggunakan pendekatan kualitatif dengan pendekatan wacana konstruktivisme. Dalam hal ini, Hikam dalam Eriyanto (2015) menyebutkan bahwa terdapat tiga pandangan, yaitu positivisme-empiris dimaksudkan untuk menunjukkan kebenaran atau ketidak benaran dalam tata bahasa secara gramatikal, konstruktivisme untuk membongkar maksud dan makna dalam suatu bahasa untuk melihat maksud tersembunyi saat suatu subjek mengemukakan suatu kalimat atau pernyataan, sedangkan wacana kritis merupakan penekanan terhadap konstelasi kekuatan yang ada pada proses produksi dan reproduksi makna yang dipengaruhi dengan kekuatan sosial yang ada pada masyarakat. Wacana konstruktivisme dalam penelitian ini digunakan untuk memahami dan 
menganalisis kegiatan preservasi nilai-nilai kearifan lokal pada local content naskah Pararaton pada Novel Arok Dedes.

Metode pengumpulan data menggunakan analisis dokumen, yang dilakukan dengan cara membaca secara keseluruhan isi Novel Arok Dedes - sebagai objek penelitian ini dan naskah Pararaton sebagai dokumen verifikator. Data penelitian ini dianalisis menggunakan analisis wacana. Peneliti melihat kesamaan wacana yang dimiliki Naskah Pararaton dan Novel Arok Dedes. Hasil analisis wacana pada kedua naskah tersebut kemudian dibandingkan. dengan cara menentukan kelompok dalam kategori plot atau alur cerita yang membentuk cerita Ken Arok dan Ken Dedes dalam naskah Pararaton. Kemudian, plot tersebut dibandingkan dalam cerita Ken Arok dan Ken Dedes yang ada pada Novel Arok Dedes untuk mengetahui kesamaan atau perbedaan ceritanya.

\section{HASIL DAN PEMBAHASAN}

\subsection{Analisis Cerita pada Naskah Pararaton}

Naskah Pararaton ditulis pada tahun 1403 Saka dengan menggunakan bahasa Jawa Tengahan. Naskah Pararaton yang diteliti merupakan naskah terjemahan dalam bahasa Indonesia. Naskah Pararaton yang diterjemahkan dalam bahasa Indonesia sudah banyak beredar di internet, file lengkapnya dapat diakses di https://ki-demang.com/index.php/pararaton/. Naskah Pararaton terdiri dari tujuh bagian atau bab, namun kisah Ken Arok dan Ken Dedes hanya diceritakan sampai bagian tiga sedangkan bagian-bagian lainnya menceritakan mengenai raja-raja yang menduduki Tumapel. Kisah raja-raja penerus takhta Tumapel hanya diceritakan secara singkat, berbeda dengan cerita Ken Arok yang permulaan ceritanya dari awal ia dilahirkan hingga wafat.

Penelitian ini membahas tentang preservasi kearifan lokal pada cerita rakyat Ken Arok dan Ken Dedes pada naskah Pararaton dalam representasi novel Arok Dedes. Proses analisis naskah Pararaton hanya dilakukan sampai bagian ketiga, yaitu sampai Ken Arok diceritakan telah wafat. Berikut pembagian plot pada naskah Pararaton bagian pertama sampai ketiga.

Tabel 1. Plot Naskah Pararaton Bagian Pertama sampai Ketiga

\begin{tabular}{|c|c|c|c|}
\hline No. & Bagian Pertama & Bagian Kedua & Bagian Ketiga \\
\hline 1 & Kelahiran Ken Arok & $\begin{array}{l}\text { Mpu Palot Orang Tua Angkat Ketiga } \\
\text { Ken Arok }\end{array}$ & Terbunuhnya Mpu Gandring \\
\hline 2 & $\begin{array}{l}\text { Lembong Orang Tua An- } \\
\text { gkat Pertama Ken Arok }\end{array}$ & Ken Arok Raja Pulau Jawa & $\begin{array}{l}\text { Kebo Hijo dengan Keris Kepunyaan } \\
\text { Ken Arok }\end{array}$ \\
\hline 3 & $\begin{array}{l}\text { Permulaan Hijrahnya Ken } \\
\text { Arok }\end{array}$ & $\begin{array}{l}\text { Pertemuan Pertama dengan Dang } \\
\text { Hyang Lohgawe }\end{array}$ & Terbunuhnya Tunggul Ametung \\
\hline 4 & $\begin{array}{l}\text { Bango Samparan Orang } \\
\text { Tua Angkat Kedua Ken } \\
\text { Arok }\end{array}$ & $\begin{array}{l}\text { Dilarikannya Ken Dedes oleh Tunggul } \\
\text { Ametung }\end{array}$ & $\begin{array}{l}\text { Pernikahan Ken Arok dengan Ken } \\
\text { Dedes, dan Istri Mudanya Ken Umang }\end{array}$ \\
\hline 5 & $\begin{array}{l}\text { Sahabat dan Guru Per- } \\
\text { tama Ken Arok }\end{array}$ & Ken Arok Melihat Rahasia Ken Dedes & Ken Arok Menguasai Tanah Jawa \\
\hline 6 & $\begin{array}{l}\text { Buronan Akuwu Tunggul } \\
\text { Ametung }\end{array}$ & $\begin{array}{l}\text { Meminta Persetujuan Kepada Dang } \\
\text { Hyang Lohgawe }\end{array}$ & Terbunuhnya Ken Arok \\
\hline 7 & $\begin{array}{l}\text { Persembunyian Ken Arok } \\
\text { dalam Keluarga Kepala } \\
\text { Daerah }\end{array}$ & Persetujuan Bango Samparan & - \\
\hline 8 & - & Pertemuan dengan Mpu Gandring & - \\
\hline
\end{tabular}


ditentukan dalam naskah Pararaton merupakan alur cerita yang membentuk cerita Ken Arok dan Ken Dedes pada naskah Pararaton.

Nurgiyantoro (1998) mengatakan bahwa plot merupakan unsur yang penting dalam suatu cerita, karena plot menunjukkan struktur linear suatu penyajian peristiwa dalam karya fiksi sehingga ada keterkaitan antar-peristiwa yang akan mempermudah pemahaman mengenai cerita yang digambarkan. Penentuan plot pada naskah Pararaton akan mempermudah untuk memahami cerita mengenai Ken Arok dan Ken Dedes pada naskah Pararaton.

Plot merupakan penyederhanaan cerita Ken Arok dan Ken Dedes pada naskah Pararaton. Plot dapat digunakan sebagai titik akses informasi dan menyederhanakan suatu informasi yang ada pada naskah Pararaton. Plot digunakan sebagai titik akses yang dicocokan dengan cerita Ken Arok dan Ken Dedes yang ada pada novel Arok Dedes untuk melihat adanya kesamaan dan perbedaan atau tidak diceritakan kembali pada novel. Pleshkevich dalam Sudarsono (2016) mengatakan bahwa substansi dari sebuah dokumen adalah informasi atau pengetahuan dan ketika dokumen yang didalamnya mengandung informasi untuk pendokumentasian.

\subsection{Analisis Preservasi Kearifan Lokal Naskah Pararaton dalam Novel Arok Dedes}

Novel Arok Dedes menceritakan mengenai tokoh Ken Arok yang berkeinginan untuk mengambil kedudukan akuwu di Tumapel milik Tunggul Ametung. Konten yang ada pada naskah Pararaton dan novel Arok Dedes memiliki beberapa perbedaan. Penyebabnya adalah adanya perbedaan tujuan yang dimiliki oleh masing-masing dokumen dan perbedaan zaman ketika penulisan dokumen. Perbedaan yang dimiliki kedua dokumen terlihat jelas dari dua puluh satu plot yang sudah ditentukan dalam naskah Pararaton, hanya lima belas plot yang diangkat kembali pada novel Arok Dedes.

Bagian pertama pada naskah Pararaton terdapat tujuh plot yang digambarkan kembali dalam novel Arok Dedes. Bagian kedua pada naskah Pararaton terdapat delapan plot namun yang digambarkan kembali dalam novel Arok Dedes hanya lima plot. Bagian ketiga pada naskah Pararaton terdapat enam plot namun yang digambarkan kembali dalam novel Arok Dedes hanya empat plot, sehingga terdapat lima belas plot yang sudah ditentukan dalam naskah Pararaton digambarkan kembali dalam novel Arok Dedes. Dalam plot yang sudah ditentukan terkandung nilai kearifan lokal yang tersirat. Hal tersebut dapat dilihat pada halaman 53 novel Arok Dedes.

"Jangan, jangan teruskan sekarang. Ada waktunya kau ucapkan semua itu di suatu tempat yang lebih baik. Yang kudengar bukan lagi keluar dari mulut seorang calon Brahmana. Itu lebih patut diucapkan oleh seorang calon, di medan perang, di medan tikai, kemudian di atas singgasana."

\footnotetext{
"Ia buka tangan dari mulut muridnya, melepas destar pemudah itu, mencium ubun-ubunnya. Dengan api, Hyang Bathara Guru dalam dadamu, dengan ketajaman parasyu Hyang Ganesya, dengan keperkasaan Hyang Durga Mahisasuramardini, kaulah Arok, kaulah pemangun ajaran, pembangun negeri sekaligus. Dengarkan kalian semua, sejak detik ini, dalam kesaksian Hyang Bathara Guru, yang berpadu dalam Brahma, Syiwa dan Wisynu dengan semua syaktinya, aku turunkan pada anak ini nama yang akan membawanya pada kenyataan sebagai bagian dari cakrawati, kenyataan itu kini masih membara dalam dirimu. Arok namamu. Semua murid mengangkat sembah (Toer, 2000)”.
}

Isi pada novel Arok Dedes di atas, Ken Arok diyakini sebagai raja oleh Gurunya, Dang Hyang Lohgawe, yang merupakan kaum Brahmana. Dalam naskah Pararaton juga menceritakan bahwa Ken Arok diyakini sebagai raja di Pulau Jawa oleh para dewa. Berikut ini penggambaran yang dituliskan dalam halaman 12 naskah Pararaton.

Demikianlah kata para dewa, saling mengemukakan pembicaraan: "Siapakah yang pantas menjadi raja di pulau Jawa?" demikian pertanyaan para dewa semua. Menjawablah dewa Guru: "Ketahuilah dewa-dewa semua, adalah anakku, seorang manusia yang lahir dari orang Pangkur, itulah yang memperkokoh tanah Jawa." Kini keluarlah Ken Angrok dari tempat sampah, dilihat, oleh para dewa; semua dewa menjetujui, ia direstui bernama nobatan Batara Guru, demikian itu pujian dari dewa-dewa, yang bersorak-sorai riuh 
rendah. Diberi petunjuklah Ken Angrok agar mengaku ayah kepada seorang Brahmana yang bernama Dang Hyang Lohgawe. Dia ini baru saja dari Jambudipa, disuruh menemuinya di Taloka. Itulah asal mulanja ada brhamana di sebelah timur Kawi. (n.n., 2011)

Kesamaan cerita antara naskah Pararaton dan novel Arok Dedes di atas, terdapat nilai kearifan lokal berupa politik tradisional yang dianut pada zaman kerajaan Singasari. Politik tradisional yang dianut adalah berupa ramalan masa depan. Mu'minin (2015) mengatakan bahwa Ken Arok dalam ceritanya menggambarkan mengenai politik tradisional. Peristiwa Ken Arok menjadi raja di Jawa karena adanya campur tangan dari para dewa dan brahmana yang diyakini memiliki pandangan masa depan atau wangsit yang diperoleh pada saat kaum Brahmana bersemedi. Dengan melihat kesamaan konten yang ada pada naskah Pararaton dan novel Arok Dedes mengenai Ken Arok yang akan menggantikan kedudukan kerajaan Tumapel maka nilai kearifan lokal mengenai politik tradisonal berupa visi masa depan yang dapat dilestarikan dan diakses informasinya oleh masyarakat.

Menurut Amin (2011), naskah kuno merupakan bukti adanya tradisi di tengah masyarakat yang menggambarkan kemajuan peradaban mengenai ketuhanan, budi pekerti, sejarah, cerita rakyat, teknologi tradisional, mantra, silsilah, jimat, syair, politik, pemerintahan, undang-undang, hukum adat, pengobatan tradisional, dan hikayat. Sudarsono dalam Latiar (2018) mengatakan bahwa naskah kuno merupakan salah satu warisan budaya bangsa yang paling otoratif dan paling otentik dalam memberikan informasi mengenai sejarah pada masa tertentu dengan mencerminkan berbagai pemikiran, pengetahuan, adat istiadat, serta perilaku masyarakat masa lalu. Mengacu pendapat tersebut, naskah kuno merupakan naskah yang didalamnya terkandung informasi sejarah mengenai perilaku masyarakat pada masa naskah tersebut dituliskan. Informasi yang terkandung dalam naskah Pararaton memuat nilai kearifan lokal yang menggambarkan politik tradisional pada zaman kerajaan Singasari.

Nilai kearifan lokal pada cerita rakyat mudah sekali terlupakan pada generasi masa kini. Generasi muda masa kini tidak menyukainya dan lebih menyukai budaya Barat yang sering dikenalkan oleh pendidikan di sekolah-sekolah (Sudikan dalam Yetti, 2015). Penulisan kembali atau produksi dokumen dari naskah Pararaton ke novel Arok Dedes dapat membuka titik akses baru yang dapat memicu keinginan masyarakat untuk mengetahui kisah Ken Arok lebih mendalam dengan mengakses sumber lainnya. Menurut Pager (2012), kebudayaan tradisional perlu dikembangkan dengan kreativitas yang tinggi tanpa mengubah data aslinya sehingga kebudayaan tradisional tidak akan berhenti pada titik tertentu. Kebudayaan tradisional perlu disesuaikan dengan budaya populer agar tidak mudah dilupakan oleh masyarakat.

Ray Browne dalam Delaney (2007) menjelaskan bahwa budaya populer terdiri dari aspek sikap, perilaku, kepercayaan, adat istiadat, dan selera pada masyarakat manapun. Bentuk sumber budaya populer adalah media massa, musik populer, film, televisi, radio, video game, buku, dan internet. Sumber budaya populer di sini adalah karya sastra, salah satunya adalah novel. Produksi dokumen dari naskah Pararaton ke novel Arok Dedes dilakukan agar konten mengenai Ken Arok dapat lestari dengan menyesuaikan perkembangan masyarakat masa kini. Suzanne Briet dalam Buckland (1997) mengatakan bahwa menyimpan dan memelihara dokumen dapat digunakan sebagai akses ke informasi yang telah dikutip sebagai bukti dari suatu pernyataan.

Produksi dokumen tidak hanya merubah bentuk fisik dokumen lama ke dokumen baru saja, tetapi juga perpindahan informasi yang ada pada dokumen lama ke dokumen baru. Suzanne Briet dalam Sudarsono (2016) mengatakan bahwa dokumen tidak hanya sebatas wujud fisik saja namun juga mengenai tanda dan simbol yang diabadikan untuk menunjukkan fenomena konseptual atau fisik. Hidayah dalam Bahar dan Mathar (2015) menambahkan bahwa preservasi tidak hanya menyangkut hal fisik namun mencakup informasi yang terkandung didalamnya. Dapat dikatakan bahwa memproduksi suatu dokumen dapat dilakukan dengan memindahkan konten dokumen lama 
ke dokumen baru, guna menarik minat pengguna dan mempreservasi informasi yang ada pada dokumen lama.

Mempreservasi nilai kearifan lokal yang ada pada naskah Pararaton merupakan hal yang penting. Anggawira \& Salim (2019) mengatakan bahwa konten yang mengandung nilai kearifan lokal seperti sejarah, ilmiah, pendidikan, agama, dan budaya perlu dilestarikan agar dapat ditemukan kembali dan relevan dalam kehidupan masa kini, sehingga dapat menjembatani antara kebudayaan pada masa lalu, masa kini, dan masa depan. Hendrawati (2018) menambahkan bahwa naskah kuno mampu menggambarkan pola pikir dan aktivitas kehidupan masyarakat zaman dahulu, pola pikir tersebut mampu mengandung informasi mengenai bagaimana membentuk masyarakat sebagai bangsa yang beradab, informasi tersebut sangat penting untuk diketahui masyarakat masa kini.

Kegiatan meproduksi dokumen lama naskah Pararaton ke dokumen baru, novel Arok Dedes, merupakan bentuk dari kemas ulang informasi. Dongardive dalam Tupan dan Nashihuddin (2015) menjelaskan bahwa kemas ulang informasi merupakan proses seleksi, analisis, dan konsolidasi suatu informasi dalam bentuk yang lebih sesuai sehingga dapat digunakan oleh pengguna. Dapat dikatakan bahwa kegiatan produksi naskah Pararaton ke novel Arok Dedes merupakan kegiatan kemas ulang informasi yang bertujuan untuk memenuhi kebutuhan informasi pengguna.

Fatmawati (2009) mengatakan bahwa kemas ulang informasi berfungsi mempermudah pengguna dalam menemukan informasi, menghemat waktu, tenaga dan biaya, sebagai sarana penyebaran informasi yang efektif dan efisien, sebagai alat bantu penerjemahan, dan serta sebagai media dalam memenuhi kebutuhan informasi pengguna. Pengguna merupakan hal penting dalam melakukan kemas ulang informasi atau produksi dokumen lama ke dokumen baru. Dongardive (2013) menjelaskan bahwa kemas ulang informasi merupakan proses pengemasan ulang informasi dengan cara menggabungkan informasi dalam bentuk yang lebih cocok sehingga dapat digunakan oleh pengguna.

Suzanne Briet dalam Sudarsono (2016) menegaskan bahwa pengguna merupakan jantung kegiatan dokumentasi, sehingga dalam pembuatan kemas ulang informasi harus memperhatikan selera atau kebutuhan informasi masyarakat. Selera masyarakat yang sering mengalami perubahan dari waktu ke waktu, disebut sebagai test of time. Menurut Musthafa (2008), suatu karya yang sudah lama masih dinikmati atau diminati oleh masyarakat, dan hal ini merupakan karakteristik test of time. Dengan demikian, pendokumentasian naskah kuno perlu memperhatikan minat masyarakat. Kegiatan mengikuti minat masyarakat masa kini merupakan upaya dari kegiatan preservasi naskah Pararaton yang bentuk fisik dokumennya lebih diminati dalam bentuk novel Arok Dedes.

Upaya preservasi naskah Pararaton tidak hanya mengubah bentuk fisik dokumen yang menyesuaikan selera masyarakat, namun adanya pelestarian kearifan lokal yang ada pada cerita Ken Arok dan Ken Dedes dalam naskah Pararaton. Naskah Pararaton dalam novel Arok Dedes juga menunjukkan indikasi kuat terjadinya tahap pelestarian kearifan lokal yang ditemukan oleh World-Bank (1998), yaitu mengenali dan identifikasi, validitas, perekaman dan dokumentasi, penyimpanan, transfer dan penyebaran.

1. Mengenali dan mengidentifikasi terlihat dari kesamaan tokoh cerita yang ada pada naskah Pararaton dengan novel Arok Dedes, kesamaan tokoh menjadi salah satu kunci bahwa novel Arok Dedes menceritakan mengenai tokoh Ken Angrok dan Ken Dedes yang ada pada naskah Pararaton.

2. Validitas terlihat pada saat konten yang ada pada naskah Pararaton dan novel Arok Dedes dibandingkan dan menemukan kesamaan makna yang ingin disampaikan antara kedua dokumen. Saat cerita Ken Arok dan Ken Dedes dibaca pada novel Arok Dedes lalu pengguna memiliki dorongan membaca cerita Ken Arok dan Ken Dedes di naskah Pararaton dan menyadari adanya kesamaan cerita, maka tervalidasi bahwa cerita Ken Arok dan Ken Dedes yang ada pada novel Arok Dedes mengangkat cerita Ken Arok dan Ken Dedes yang ada pada naskah Pararaton. 
3. Perekaman dan dokumentasi terlihat ketika ada kesamaan cerita Ken Arok dan Ken Dedes pada novel Arok Dedes dan naskah Pararaton membuktikan adanya pesan moral dalam cerita tersebut. Pesan moral bersumber dari ambisi Ken Arok untuk mendapatkan kedudukan yang dimiliki oleh Tunggul Ametung dengan menghalalkan segala cara yang pada akhirnya berujung kepada kematian Ken Arok oleh Anusapati (Kemdikbud, 2015).

4. Transfer konten dari dokumen lama ke dokumen yang lebih baru juga dapat memperpanjang umur penyimpanan dokumen. Naskah Pararaton yang umurnya sudah tua sehingga rentan terhadap kerusakan fisik. Perpindahan mengenai cerita Ken Arok dan Ken Dedes dapat terus dikonsumsi atau diakses oleh pengguna meskipun naskah Pararaton mengalami kerusakan. Tidak hanya memperpanjang umur fisik pada naskah Pararaton saja, tetapi juga memperpanjang konten pada naskah Pararaton sehingga dapat tersimpan lebih lama dan dapat terus digunakan dari generasi ke generasi.

5. Transfer dan penyimpanan mempengaruhi terjadinya penyebaran cerita mengenai Ken Arok dan Ken Dedes kepada masyarakat yang lebih luas. Novel Arok Dedes membuka titik akses baru untuk cerita Ken Arok dan Ken Dedes yang ada pada naskah Pararaton. Titik akses baru mengenai cerita Ken Arok dan Ken Dedes pada novel Arok Dedes dapat dikonsumsi kembali dengan memperhatikan selera masyarakat masa kini.

Penggambaran kembali dalan novel Arok Dedes merupakan produksi dokumen baru dari naskah Pararaton, sehingga informasi mengenai politik tardisional dan pesan moral yang terkandung di dalamnya dapat tersimpan lebih lama dan tersebar ke masyarakat masa kini.

\section{KESIMPULAN}

Novel Arok Dedes merupakan hasil produksi dokumen dari naskah Pararaton, yang membuka titik akses baru cerita Ken Arok dan Ken Dedes pada naskah Pararaton. Produksi dokumen berupa novel Arok Dedes merupakan wujud proses preservasi kearifan lokal yang ada pada naskah Pararaton, dengan tema politik tradisional yang syarat dengan pesan moral, yaitu suatu pencapaian seyogyanya tidak berbalut dengan keinginan ambisius. Produksi dokumen dari naskah Pararaton ke novel Arok Dedes memunculkan peluang untuk meningkatkan minat masyarakat dalam mengakses cerita rakyat Ken Arok dan Ken Dedes yang berkarakter test of time. Kegiatan produksi naskah Pararaton ke novel Arok Dedes melalui enam tahapan yaitu mengenali dan identifikasi, validitas, perekaman dan dokumentasi, penyimpanan, transfer dan penyebaran. Peneliti menyarankan agar penulis karya sastra dapat mengangkat local content pada karyanya sehingga local content dapat terus lestari dengan mengikuti perkembangan zaman sehingga dapat digunakan masyarakat dari generasi ke generasi. Novel Arok Dedes diharapkan dapat memberi inspirasi bagi penulis karya sastra lainnya, dan menginspirasi content creator untuk mengangkatnya ke budaya populer melalui film, sandiwara radio, komik online, dan media online yang lain.

\section{DAFTAR PUSTAKA}

Amin, F. 2011. Preservasi Naskah Klasik. Jurnal Katulistiwa, 1(1), 89-100.

Anggawira, D. \& Salim, T. A. 2019. The Implementation of Indigenous Knowledge in Preserving Universitas Indonesia Library's Manuscripts. International Review of Humanities Studies, 4(1), 203-414.

Bahar, H. \& Mathar, T. 2015. Upaya Pelestarian Naskah Kuno di Badan Perpustakaan dan Arsip Daerah Provinsi Sulawesi Selatan. Jurnal Ilmu Perpustakaan, Informasi, dan Kearsipan Khizanah AlHikmah, 3(1), 89-100.

Buckland, M. K. 1997. What Is a Document? Journal of The American Society for Information Science, 48(9), 804-809. 
Delaney, T. 2007. Pop Culture: An Overview. PhilPapers.

Dewi, T. K. S. 2013. Arok Dedes dan Pararaton: Transformasi dan Dinamika Sastra dalam Wacana Global Sastra. ATAVISME: Jurnal Ilmiah Kajian Sastra, 16(1), 119-128.

Dongardive, P. 2013. Information Repackaging in Library Services. International Journal of Science and Research, 2(11), 204-209.

Eriyanto, E. 2015. Analisis Wacana: Pengantar Analisis Teks Media. Yogyakarta: LKiS

Fadli, M., Erwina, W., \& Prahatmaja, N. 2012. Preservasi Pengetahuan Masyarakat Minangkabau tentang Tradisi Lisan Pasambahan melalui Kegiatan Exchange of Indigenous Knowledge. Journal Mahasiswa dan Pasca Sarjana Universitas Padjajaran, 1(1), 1-14.

Fatmawati, E. 2009. Kemas Ulang Informasi: Suatu Tantangan Bagi Pustakawan. Media Pustakawan, 16(1\&2), 23-27.

Hamid, S, A, 2013. Penerjemahan Manuskrip di Lombok: Suatu Usaha untuk Memahami Nilai Budaya Sasak. Jurnal Ilmiah Bahasa dan Sastra, 7(2), 75-83.

Hendrawati, T. 2018. Digitalisasi Manuskrip Nusantara Sebagai Pelestari Intelektual Leluhur Bangsa. Media Pustakawan, 25(4), 24-32.

Hidayat, W. A., Sulistyowati, E. D., \& Rokhmansyah, A. 2019. Struktur dan Fungsi Cerita Rakyat Benayuk Versi Desa Sepala Dalung Kabupaten Tana Tidung: Kajian Strukturalisme Naratologi. Ilmu Budaya: Jurnal Bahasa, Sastra, Seni, dan Budaya, 3(4), 442-452.

Jayapada, G., Faisol, \& Kiptiyah, B. M. 2017. Kearifan Lokal dalam Cerita Rakyat sebagai Media Pendidikan Karakter untuk Membentuk Literasi Moral Siswa. BIBLIOTIKA: Jurnal Kajian Perpustakaan dan Informasi, 1(2), 60-62.

Kemendikbud, I. 2015. Ketika Ken Arok Hadir di Masa Kini. https://kebudayaan.kemdikbud.go.id/ munas/ketika-ken-arok-hadir-di-masa-kini/

Latiar, H. 2018. Preservasi Naskah Kuno sebagai Upaya Pelestarian Budaya Bangsa. Al-Kuttab: Jurnal Perpustakaan dan Informasi, 5(1), 67-83.

Mu'minin, M. 2015. Bahasa, Sastra, dan Kekuasaan. Makalah Seminar Nasional Jurusan PBSI FBS Universitas Negeri Yogyakarta.

Munandar, A. A. 2011. Menafsirkan Ulang Riwayat Ken Angrok dan Ken Dedes dalam Kitab Pararaton. Jurnal Manassa: Berkala Ilmiah Pernaskahan Nusantara, 1(1), 1-15.

Musthafa, B. 2008. Teori dan Praktik Sastra: Dalam Penelitian dan Pengajaran. Bandung: Sekolah Pascasarjana Universitas Pendidikan Indonesia.

n.n. 2011. Kitab Pararaton. Terj. Ki Demang Sokowaten. Diunduh dari https://ki-demang.com/index. php/pararaton/

Nurgiyantoro, B. 1998. Teori Pengkajian Fiksi. Yogyakarta: Gadjah Mada University Press.

OECD, U. 2011. The Relationship Between Local Content, Internet Development and Access Prices. Organisation for Economic Co-operation and Development (OECD), the Internet Society (ISOC), $\&$ United Nations Educational, Scientific and Cultural Organization (UNESCO).

Pager, S. A. 2012. Folklore 2.0: Preservation Through Innovation. Digital Commons at Michigan State University College of Law, 507: 1835-1895.

Sudarsono, B. 2016. Menuju Era Baru Dokumentasi. Jakarta: LIPI Press.

Toer, P. A. 2000. Arok Dedes. Jakarta: Hasta Mitra.

Tupan, T. \& Nashihuddin, W. 2015. Kemas Ulang Informasi untuk Pemenuhan Kebutuhan Informasi Usaha Kecil, Menengah: Tinjauan Analisis di PDII-LIPI. BACA: Jurnal Dokumentasi dan Informasi, 36(2), 109-124.

Turner, D. 2007. Conceptualizing Oral Documents. Proceeding of the Sixth International Conference on Conceptions of Library and Information Science, Seattle, USA. 
Wildan, W. 2013. Kearifan Lokal dalam Novel Seulusoh Kasrya D. Kemalawati. Jurnal Bahasa, Sastra, Seni, dan Pengajarannya. 41(1), 30-39.

World-Bank, W. 1998. Indigenous Knowledge for Development: A Framework for Action. Africa: Knowldege and Learning Center.

Yetti, E. 2015. Struktur Naratif Tuter Cerita “Tongtonge” dari Sumbawa. Sawerigading, 21(3), 505-517. 